ISSN: 2542-0259

О Российское конкурентное право и экономика, 2019
Основания смягчения

и освобождения от ответственности за нарушение антимонопольного законодательства

\section{И.В. Акимова,}

Финансовый университет при Правительстве РФ, Адвокатское бюро BGP Litigation, г. Москва

\section{Л.В. Вовкивская,}

Финансовый университет при Правительстве РФ, ФАС России, г. Москва

\section{Аннотация}

Рассмотрены ключевые положения правовых институтов смягчения и освобождения от ответственности за нарушения положений российского антимонопольного законодательства, спорные вопросы практики применения института смягчения и освобождения от ответственности. Исследованы предложения по совершенствованию законодательной регламентации названных институтов и практики их применения. Цель: создание теоретических предпосылок для совершенствования законодательной регламентации институтов смягчения и освобождения от ответственности за нарушение антимонопольного законодательства.

Выводы: сделан вывод о том, что институты смягчения и возможность освобождения от ответственности за нарушения антимонопольного законодательства должны применяться с учетом специфики конкретного правонарушения и быть направлены на соблюдение баланса частных и публичных интересов, принципов соразмерности, индивидуализации, справедливости и неотвратимости мер административной ответственности.

Ключевые слова: антимонопольное законодательство, административная ответственность, правонарушение, смягчение административной ответственности, освобождение от административной ответственности, применение наказания ниже низшего предела, малозначительность.

\title{
Legal bases of leniency and exemption from liability for violation of the antimonopoly legislation
}

\section{V. Akimova,}

Financial University under the Government of the Russian Federation,

Lawyer bureau BGP Litigation, Moscow

L. V. Vovkivskaya, Financial University under the Government of the Russian Federation, FAS Russia, Moscow

\section{Annotation}

The article consideres the key provisions of legal institutions of leniency and exemption from liability for violation of the antimonopoly legislation, controversial issues of application practice of institution of leniency and exemption from liability. The article investigates the proposals of legislative regulation improvement of above-stated institutions and their application practice.

Objective: creation of theoretical prerequisites for legislative regulation improvement for the institutions of leniency and exemption from liability for violation of the antimonopoly legislation.

Summary: the article concludes that the institutions of leniency and exemption from liability for violation of the antimonopoly legislation should be applied according to the specifics of a particular offense and should be aimed at private and public interests balancing, principles of proportionality, individualization, equity, the inevitability of administrative responsibility measures.

Keywords: antimonopoly legislation, administrative liability, offence, leniency from administrative liability, exemption from administrative liability, sanction application below the lower limit, insignificance. 
Основания смягчения и освобождения от ответственности за нарушение...

$\Pi$ роблемам применения институтов смягчения ответственности за нарушения антимонопольного законодательства и освобождения от нее посвящено значительное число научных публикаций [1-3]. В силу специфики и сложности отношений, которые составляют предмет антимонопольного регулирования, и в условиях стремительно изменяющихся рынков грань, проходящая между правомерным поведением и правонарушением, становится все менее четкой. При этом ответственность за нарушение антимонопольного законодательства, налагаемая на правонарушителей, достаточно велика. В особенности если речь идет о применении оборотного штрафа, рассчитываемого от объема выручки правонарушителя, или о взыскании в бюджет незаконно полученного дохода. Поэтому при рассмотрении дел о нарушении антимонопольного законодательства необходимо всестороннее, полное и объективное выяснение всех фактических обстоятельств дела для его разрешения в соответствии с законом и применения соответствующих мер антимонопольного реагирования, включая привлечение к административной ответственности.

Общие правила назначения административного наказания установлены ст. 4.1 Кодекса Российской Федерации об административных правонарушениях (далее КоАП РФ) [4], в соответствии с которой при назначении административного наказания юридическому лицу учитываются характер совершенного им административного правонарушения, имущественное и финансовое положение юридического лица, обстоятельства, смягчающие административную ответственность, и обстоятельства, отягчающие административную ответственность.

Следуя принципу индивидуальности и соразмерности наказания, законодательством предусмотрены основания для смягчения и освобождения от ответственности за нарушения антимонопольного законодательства, и их своевременное выявление необходимо для правильного применения мер ответственности за установленное нарушение. В связи с этим представляется актуальным рассмотрение основных вопросов, возникающих при применении смягчающих обстоятельств при привлечении к ответственности за нарушение антимонопольного законодательства, и основания освобождения от ответственности

\section{Обстоятельства, смягчающие ответственность}

Институт смягчения ответственности применим только в публичных отношениях, т. е. применяется при привлечении к административной или уголовной ответственности.

Если обратиться к нормам, закрепленным в КоАП РФ, то можно выделить следующие три группы смягчающих обстоятельств.

$K$ первой группе относятся указанные в ч. 1 ст. 4.2 КоАП РФ обстоятельства, которые применимы ко всем составам правонарушений, предусмотренным КоАП РФ. При этом обстоятельства, предусмотренные п. 2-7 указанной выше части, применяются в отношении юридических лиц за нарушение антимонопольного законодательства, что прямо предусмотрено примечаниями К ст. 14.31 и 14.32 КоАП РФ. К таким обстоятельствам КоАП РФ относит: 1) добровольное прекращение совершения противоправных действий; 2) добровольное сообщение о совершенном правонарушении; 3) оказание содействия административному органу; 4) предотвращение вредных последствий правонарушения; 5) добровольное возмещение вреда и устранение ущерба; 6) добровольное исполнение предписания до вынесения постановления о привлечении к ответственности.

Следует отметить, что закон прямо не предусматривает возможность использования полного перечня смягчающих обстоятельств в отношении лиц, привлекаемых к ответственности за нарушение антимонопольного законодательства.

Ко второй групnе смягчающих обстоятельств КоАП РФ относит обстоятельства, применимые только к конкретному составу правонарушения в сфере антимонопольного права, а именно к антиконкурентным соглашениям и согласованным действиям. В соответствии с примечанием к ст. 14.32 КоАП РФ обстоятельствами, смягчающими ответственность, являются обстоятельства, подтверждающие, что лицо не является организатором антиконкурентных соглашений и согласованных действий; лицо не приступило к исполнению соглашения.

Третью группу составляют иные смягчающие обстоятельства, не перечисленные в КоАП РФ.

Положениями ч. 2 ст. 4.2 КоАП РФ установлено, что судья, орган, должностное лицо, рассматривающие дело об административном правонарушении, могут признать смягчающими обстоятельства, не указанные в КоАП РФ или в законах субъектов РФ об административных правонарушениях. Таким образом, перечень обстоятельств, смягчающих административную ответственность, установленный законодателем, не является исчерпывающим. Это обязывает уполномоченный орган учитывать в качестве смягчающих обстоятельств те обстоятельства, которые перечислены в ч. 1 ст. 4.2 КоАП РФ, и наделяет его правом учесть иные, не поименованные в данной статье обстоятельства в качестве смягчающих административную ответственность исходя из конкретных обстоятельств дела об административном правонарушении.

Но на практике вопрос о том, является ли перечень смягчающих обстоятельств для применения за нарушение антимонопольного законодательства открытым, является дискуссионным. Правоприменительная практика антимонопольных органов показывает, что орган исходит из закрытости перечня смягчающих обстоятельств при привлечении к ответственности за нарушение антимонопольного законодательства, то есть не учитывает 
смягчающие обстоятельства, прямо не поименованные в законе.

Например, в решении ФАС России о рассмотрении жалобы на постановление по делу об административном правонарушении № 4-14.32-91/00-22-18 антимонопольный орган, ссылаясь на позиции судов, указывает, что в ст. 14.32 КоАП РФ список смягчающих обстоятельств носит исчерпывающий характер и совершение правонарушения впервые не может быть рассмотрено в качестве такового [5].

Между тем данный подход антимонопольного органа не всегда находит поддержку судов. Так, в постановлении суда апелляционной инстанции по делу № А08-9287/2016 указано, что конституционные требования справедливости и соразмерности предопределяют по общему правилу необходимость дифференциации юридической ответственности в зависимости от тяжести содеянного, размера и характера причиненного ущерба, степени вины правонарушителя и иных существенных обстоятельств, обусловливающих индивидуализацию при выборе той или иной меры государственного принуждения, на что неоднократно указывал Конституционный Суд Российской Федерации [6]. При этом приведенное антимонопольным органом толкование ст. 4.2 и примечания 3 к ст. 14.32 КоАП РФ как устанавливающих исчерпывающий перечень смягчающих обстоятельств по сути означает невозможность осуществить дифференциацию административной ответственности за нарушение антимонопольного законодательства в зависимости от тяжести содеянного, размера и характера причиненного ущерба, степени вины правонарушителя и иных существенных обстоятельств, поскольку не позволяет учесть прямо не предусмотренные законом обстоятельства в качестве смягчающих, даже при наличии таковых. При этом общественная опасность правонарушений в сфере антимонопольного законодательства сама по себе не может являться достаточным основанием для отступления от конституционных принципов применения административной ответственности.

Но даже практика самих антимонопольных органов по данному вопросу не столь единообразна.

Например, постановлением ФАС России от 17.04.2017 по делу № 4-19.5-11/00-08-17 такое обстоятельство, как совершение правонарушения, впервые было учтено в качестве смягчающего [7]. Встречаются случаи признания довольно специфических обстоятельств в качестве смягчающих, например, таких как «неагрессивность рекламы» (постановление ФАС Волго-Вятского округа от 12.03.2010 по делу № А29-1325/2009) [8].

Зачастую в качестве иного смягчающего обстоятельства может выступать антимонопольный комплаенс. К примеру, в решении по делу № 1-11-59/00-22-16 в отношении 000 «Эппл Рус» антимонопольным органом приняты во внимание меры, направленные на совершенствование системы уже существующего анти- монопольного комплаенса. Как отметила ФАС России, «...по мнению Комиссии, перечисленные выше меры по усилению и повышению качества мер антимонопольного комплаенса, планируемые к принятию 000 “Эппл Рус”, могут быть эффективными для предупреждения совершения данным лицом нарушений антимонопольного законодательства Российской Федерации в будущем...» [9].

В настоящее время существуют предложения о внесении изменений в КоАП РФ, рассматривающих в качестве смягчающего обстоятельства антимонопольный комплаенс, т. е. внутрикорпоративную систему предупреждения антимонопольных рисков.

Одним из практических вопросов является регламентация порядка и сроков подачи ходатайства о смягчении ответственности. В соответствии с ч. 1 ст. 25.1 КоАП РФ лицо, в отношении которого ведется производство по делу об административном правонарушении, имеет право в том числе подавать ходатайства. Логично предположить, что указанное право лицо может реализовать до момента вынесения постановления о привлечении к административной ответственности.

КоАП РФ устанавливает обязательную письменную форму для таких ходатайств (ст. 24.4). При этом Верховный Суд Российской Федерации в Обзоре законодательства и судебной практики за третий квартал 2010 г. указывает, что лицо может подать ходатайство телеграммой, заверенной оператором связи и содержащей сведения, позволяющие идентифицировать такое лицо (ФИО, адрес лица, его подпись) [10].

Также отсутствуют правила, устанавливающие необходимое содержание для такого ходатайства. Тем не менее для того, чтобы антимонопольный орган смог учесть представленные сведения и сделать вывод о наличии смягчающих обстоятельств, такое ходатайство должно содержать:

- описание обстоятельств совершения правонарушения;

- перечень смягчающих обстоятельств, по мнению привлекаемого к ответственности лица, подлежащих применению;

- подробную мотивацию необходимости применения смягчающих обстоятельств (с приложением подтверждающих документов);

- ссылки на соответствующие положения Федерального закона «О защите конкуренции» от 26.07.2006 № 135-Ф3 [11] (далее - Закон о защите конкуренции) и КоАПРФ;

- ссылки на подходящую судебную практику;

- сформулированную просьбу к антимонопольному органу о смягчении штрафных санкций с учетом смягчающих обстоятельств (допускается указать сумму, до которой хотелось бы получить снижение);

- дату составления ходатайства и подпись заявителя.

Но не следует забывать, что, как отмечено в постановлении Конституционного Суда Российской Федерации 
Основания смягчения и освобождения от ответственности за нарушение...

(далее - КС РФ) от 17.02.2016 № 5-П, закрепление в действующем правовом регулировании возможности индивидуализации административного наказания не является абсолютным - согласно ч. 1 ст. 4.1 КоАП РФ оно во всяком случае должно назначаться в пределах, установленных законом, предусматривающим ответственность за конкретное административное правонарушение, и в соответствии с данным Кодексом, если иное им прямо не разрешено (ч. 22 ст. 4.1 КоАП РФ [12]).

Согласно примечанию 4 К ст. 14.31 КоАП РФ при наличии обстоятельств, смягчающих административную ответственность, за исключением обстоятельств, предусмотренных п. 5 и 6 ч. 1 ст. 4.2 КоАП РФ, размер административного штрафа, налагаемого на юридическое лицо, подлежит уменьшению за каждое такое обстоятельство на одну восьмую разности максимального размера административного штрафа, предусмотренного за совершение данного административного правонарушения, и минимального размера административного штрафа, предусмотренного за совершение данного административного правонарушения.

От института смягчения ответственности следует отличать институт назначения наказания ниже низшего предела.

\section{Назначение наказания ниже низшего предела}

Наказание ниже низшего предела может быть назначено в отношении физических, должностных и юридических лиц при наличии исключительных обстоятельств. КоАП устанавливает минимальный размер штрафа, который может быть назначен: для должностных лиц - не менее пятидесяти тысяч рублей, для юридических лиц не менее ста тысяч рублей. При этом указанный институт не применяется в отношении других видов наказаний.

Стоит отметить, что суды и административные органы до недавнего времени не имели возможности назначать наказание ниже низшего предела. Определением КС РФ от 05.11.2003 № 349-0/2003 была установлена возможность снижения минимального размера наказания только путем внесения законодательных изменений. Конституционный Суд посчитал, что указанный вопрос выходит за пределы его компетенции [13]. Верховный Суд РФ в п. 21 постановления Пленума от 24.03.2005 № 5 также указал на возможность назначения административного наказания лишь в пределах санкций, установленных законом [14].

Указанную практику изменил КС РФ постановлением от 17.01.2013 № 1-П, согласно которому системное изменение законодательства, повышение минимальных размеров штрафов привело к трудностям при назначении наказания, а именно при соблюдении принципа соразмерности наказания и его индивидуализации [15]. В связи с этим Конституционный Суд пришел к выводу, что отсутствие возможности установления штрафа ниже низшего предела не исключает превращение штрафа как наказания в инструмент подавления свободы предпринимательской деятельности и инициативы. Данная позиция нашла свое развитие в постановлении КС РФ от 25.02.2014 № 4-П, в котором указано, что федеральный законодатель обязан заботиться о реализации конституционных прав и свобод субъектов и не позволять использовать избыточный механизм административного принуждения [16].

В результате в 2015 г. Федеральным законом от 31.12.2014 № 515-Ф3 «О внесении изменений в ст. 4.1 Кодекса Российской Федерации об административных правонарушениях» была предусмотрена возможность снижения минимального размера штрафа [17].

На практике суды и административные органы нередко применяют положения ст. 4.1 КоАП РФ, согласно которой при наличии исключительных обстоятельств, связанных с характером совершенного административного правонарушения и его последствиями, имущественным и финансовым положением привлекаемого к административной ответственности лица, судья, орган, должностное лицо, рассматривающие дела об административных правонарушениях, могут назначить наказание в виде административного штрафа в размере менее минимального предусмотренного соответствующей статьей Кодекса, но не менее половины минимального размера административного штрафа, предусмотренного данной статьей.

Как правило, исключительность обстоятельств, являющихся основанием для назначения наказания ниже низшего предела, оценивается в совокупности. В частности, указанная норма может быть применена в отношении организаций, осуществляющих регулируемые, а также социально значимые виды деятельности, в силу их социально значимого статуса. Например, постановлением Пятого арбитражного апелляционного суда от 07.03.2017 № 05АП-230/2017 при назначении штрафа ниже низшего предела судом учтены статус и направление деятельности сетевой организации [18]. В другом деле Верховный Суд РФ учел то, что сетевая организация совершила правонарушение впервые, и то, что размер минимального штрафа является для нее значительным (определение Верховного Суда РФ от 04.07.2018 №310-АД18-8272) [19]. Также зачастую принимается во внимание имущественное положение лица, привлекаемого к административной ответственности (постановлением Арбитражного суда Поволжского округа от 21.07.2016 № Ф06-10542/2016 минимальный размер штрафа был снижен в два раза) [20].

Необходимо отметить, что исходя из правоприменительной практики лицо, которое ходатайствует о смягчении ответственности или о применении наказания ниже низшего предела ввиду финансового положения, должно представить соответствующие доказательства, 
подтверждающие данный факт. K таким доказательствам, в частности, могут относиться документы, подтверждающие финансовое состояние лица (бухгалтерский баланс, справка о составе активов организации, выписка с банковского счета организации).

Так, в одном деле, принимая решение, суд указал на то, что размер административного штрафа не сопоставим с характером административного правонарушения, учитывая отсутствие существенной угрозы охраняемым законом отношениям, а также учел тот факт, что общество ранее к аналогичной административной ответственности не привлекалось (постановление Арбитражного суда Северо-Кавказского округа от 17.02.2017 № Ф08-510/2017) [21]. Кроме того, согласно бухгалтерскому балансу активы общества снизились по сравнению с активами 2014 г. более чем в два раза, имеется значительная дебиторская задолженность, которая имеет тенденцию к росту. В связи с этим выплата такой значительной суммы штрафа, определенной антимонопольным органом, повлечет невозможность своевременного выполнения обществом обязательств перед заказчиками по заключенным контрактам и работниками по выплате заработной платы, приведет к задержкам выполнения налоговых обязательств и поставит общество на грань банкротства. Данные обстоятельства позволили суду снизить размер административного штрафа хозяйствующему субъекту.

Таким образом, применение института назначения наказания ниже низшего предела, подтвержденное исключительностью обстоятельств, являющихся основанием для такого снижения, может существенно способствовать уменьшению административного штрафа, что соответствует принципам соразмерности и индивидуализации наказания.

\section{Малозначительность административного правонарушения}

Малозначительным административным правонарушением является действие или бездействие, хотя формально и содержащее признаки состава административного правонарушения, но с учетом характера совершенного правонарушения и роли правонарушителя, размера вреда и тяжести наступивших последствий не представляющее существенного нарушения охраняемых общественных правоотношений (постановление Пленума Верховного Суда РФ от 24.03.2005 № 5) [22]. Поэтому в силу положений ст. 2.9 КоАП РФ при малозначительности совершенного административного правонарушения лицо, совершившее правонарушение, может быть освобождено от административной ответственности, а судья может ограничиться устным замечанием в его адрес.

Следовательно, малозначительность деяния является обстоятельством, освобождающим от административной ответственности, а правовым последствием его применения будет являться вынесение постановления о прекращении производства по делу об административном правонарушении и объявление устного замечания.

Между тем, как отмечено в указанном ранее постановлении КС РФ от 17.02.2016 №5-П, малозначительность как способ обеспечения справедливости административного наказания и его соразмерности правонарушающему деянию можно считать оправданной лишь при условии, что это деяние с учетом его характера, личности правонарушителя и тяжести наступивших последствий хоть формально и содержит признаки состава административного правонарушения, но не причиняет существенного ущерба охраняемым общественным отношениям. Однако использование такой возможности всякий раз, когда правоприменительный орган считает наказание несоразмерным, способствовало бы, как отмечал Конституционный Суд Российской Федерации в постановлениях от 17.01.2013 № 11-П и от 25.02.2014 № 4-П, формированию атмосферы безнаказанности, несовместимой с принципом неотвратимости ответственности, вытекающей из ст. 4 (ч. 2), 15 (ч. 2) и 19 (ч. 1 и 2) Конституции Российской Федерации.

Следовательно, квалификация правонарушения как малозначительного может иметь место только в исключительных случаях, при этом необходимо исходить из оценки конкретных обстоятельств совершения правонарушения. Применение положений о малозначительности должно быть мотивировано.

Согласно постановлению Пленума Верховного Суда РФ от 02.06.2004 № 10 такие обстоятельства, как, например, личность и имущественное положение привлекаемого к ответственности лица, добровольное устранение последствий правонарушения, возмещение причиненного ущерба, не являются обстоятельствами, свидетельствующими о малозначительности правонарушения. Данные обстоятельства в силу ч. 2 и 3 ст. 4.1 КоАП РФ учитываются при назначении административного наказания [23].

Аналогичные правовые подходы нашли отражение и в практике Конституционного Суда Российской Федерации. Так, в постановлении от 17.01.2013 № 1-П КС РФ указал, что малозначительность не может во всех случаях являться альтернативой назначению санкции ниже ее минимального значения, поскольку может быть нарушен принцип справедливости и неотвратимости ответственности. Поэтому имущественное и финансовое положение субъекта не учитывается в целях применения института малозначительности [24].

Статья 2.9 КоАП РФ не содержит оговорок о неприменении малозначительности к каким-либо составам правонарушений, предусмотренным КоАП РФ. Однако с учетом признаков объективной стороны некоторых административных правонарушений они ни при каких обстоятельствах не могут быть признаны 
Основания смягчения и освобождения от ответственности за нарушение...

малозначительными, поскольку существенно нарушают охраняемые общественные отношения.

В правоприменительной практике антимонопольный орган редко прибегает к применению малозначительности при рассмотрении дел об административных правонарушениях, поскольку составы правонарушений, по которым орган полномочен привлекать к административной ответственности, существенным образом нарушают публичный интерес.

Анализ практики показывает, что малозначительность применяется органом в подавляющем большинстве случаев при нарушении законодательства о контрактной системе, в частности, при непредставлении каких-либо документов, которые никак не влияют на итоги проведения закупочной процедуры. Например, постановлением ФАС России от 12.10.2017 по делу № AK451-17 [25] производство по делу об административном правонарушении было прекращено в связи с малозначительностью совершенного правонарушения (нарушение ч. 3 ст. 103 Федерального закона «О контрактной системе в сфере закупок товаров, работ, услуг для обеспечения государственных и муниципальных нужд» от 05.04.2013 № 44-Ф3 [26] (далее - Закон о контрактной системе) - не был предоставлен акт приемки поставленного товара). В другом деле должностное лицо заказчика, не разместив отчет об исполнении контракта, нарушило ч. 9 ст. 94 Закона о контрактной системе, что также было квалифицировано органом как малозначительное деяние (постановление ФАС России от 12.10.2017 по делу № АК448-17) [27].

В целях формирования единообразных подходов к практике применения института малозначительности ФАС России были разработаны методические рекомендации по применению ст. 2.9 КоАП РФ (в части прекращения дел об административных правонарушениях, связанных с нарушением антимонопольного законодательства).

Согласно данным рекомендациям должностным лицам антимонопольных органов при оценке возможности применения малозначительности следует исходить из следующего. Не могут быть квалифицированы в качестве малозначительных нарушение порядка и сроков представления в орган ходатайств, непредставление сведений по запросу либо представление недостоверных сведений, так как данное представляет угрозу общественным отношениям в сфере антимонопольного контроля. Такая угроза заключается в затруднении возможности осуществления антимонопольного контроля независимо от степени влияния на конкуренцию сделок и действий, подлежащих антимонопольному контролю [28].

Должностные лица антимонопольного органа не вправе освобождать нарушителей от административной ответственности при наличии доказательств совершения лицом правонарушений, предусмотренных ст. 14.3114.33, ч. 2.1-2.6 ст. 19.5, ч. 3-5 ст. 19.8 КоАП РФ.
И только в отдельных случаях могут быть признаны малозначительными нарушение порядка и сроков представления уведомлений (если пропуск срока незначителен - до 15 дней) и представление неполных сведений о группе лиц (к примеру, не представлена информация о лице, которая не имеет значения для принятия органом решения по рассматриваемой сделке, совершенной в уведомительном порядке в соответствии со ст. 31 Закона о защите конкуренции).

\section{Освобождение от ответственности}

В случае совершения определенных нарушений антимонопольного законодательства, а именно в случае заключения антиконкурентных соглашений и согласованных действий, хозяйствующие субъекты могут быть освобождены от ответственности при соблюдении ряда условий. В соответствии с примечанием 1 к ст. 14.32 КоАП РФ лицо освобождается от ответственности, если:

- оно добровольно заявило о правонарушении;

- на момент обращения антимонопольный орган не располагал необходимой информацией;

- лицо прекратило участие в соглашении или прекратило согласованные действия;

- информация, представленная хозяйствующим субъектом, является достаточной для установления события правонарушения;

- лицо выполнило указанные условия первым.

При этом лица, которые выполнили данные условия вторыми или третьими, вправе рассчитывать на минимальный размер штрафа (ч. 5 Примечания к ст. 14.32 КоАПРФ).

Законодательством не установлен момент, когда указанные документы и сведения могут быть представлены в антимонопольный орган. Постановлением Пленума Высшего Арбитражного Суда РФ от 30.06.2008 № 30 «О некоторых вопросах, возникающих в связи с применением арбитражными судами антимонопольного законодательства» разъяснено, что обращение в орган может состояться до установления факта нарушения, то есть до момента оглашения решения комиссией [29]. Между тем согласно практике антимонопольных органов заявление об освобождении от ответственности в порядке, установленном примечаниями к ст. 14.32 КоАП РФ, может быть подано лицом до момента выдачи заключения об обстоятельствах дела (с учетом, что такое заявление лица не содержит иной информации относительно нарушения антимонопольного законодательства, содержащейся в заключении).

При этом если лица одновременно обратились в антимонопольный орган, то заявление не будет подлежать рассмотрению при условии, что такие лица не входят в одну группу лиц. Так, решением Краснодарского УФАС России от 25.07.2018 по делу № 25/2018 субъекты, одновременно заявившие о нарушении антимонопольного 
законодательства и входящие в одну группу лиц согласно п. 7 ч. 1 ст. 9, были освобождены от ответственности за заключение антиконкурентного соглашения [30].

Из-за отсутствия законодательного закрепления соответствующей нормы на практике часто возникает вопрос о том, какие сведения могут быть признаны достаточными для установления события административного правонарушения. Данный критерий является оценочным и зависит от усмотрения антимонопольного органа. В частности, постановлением Девятого арбитражного апелляционного суда от 17.08.2012 № 09АП-15752/2012-АК было установлено, что хозяйствующий субъект, участвуя в процедуре раскрытия картеля, предоставил информацию только об одном договоре, хотя антиконкурентная договоренность состояла из нескольких договоров [31].

В настоящее время ФАС России подготовлен законопроект, которым планируется внести изменения в Закон о защите конкуренции в части уточнения порядка раскрытия антиконкурентных соглашений и согласованных действий (ID проекта 02/04/10-17/00074495) [32]. Так, законопроект устанавливает порядок обращения хозяйствующего субъекта в антимонопольный орган с целью освобождения от ответственности, перечень документов и сведения, которые должны быть представлены (данные о сторонах антиконкурентного соглашения, его основные цели и территория действия, порядок взаимодействия сторон, сведения о товарном рынке, на котором совершено нарушение, и т. п.), и порядок взаимодействия хозяйствующего субъекта и антимонопольного органа. Важным планируемым изменением является то, что до подачи сообщения хозяйствующий субъект вправе на условиях анонимности запросить у антимонопольного органа информацию о том, поданы ли в антимонопольный орган на момент обращения хозяйствующего субъекта аналогичные сообщения от иных лиц, являющихся участником того же соглашения или тех же согласованных действий. Кроме того, планируется введение института соглашений о сотрудничестве с антимонопольным органом. Законопроектом устанавливаются требования к такому соглашению и порядок его заключения. На данный момент законопроект прошел оценку регулирующего воздействия и находится на рассмотрении в Правительстве Российской Федерации.

Таким образом, действующее законодательство и существующие законодательные инициативы предусматривают широкий спектр правовых инструментов, позволяющих хозяйствующим субъектам минимизировать негативные последствия от мер антимонопольного реагирования при установлении в их действиях факта нарушения антимонопольного законодательства. Вместе с тем рассмотренные правовые институты должны обеспечивать соблюдение баланса частных и публичных интересов, принципов соразмерности и индивидуализации наказания, справедливости и неотвратимости ответственности.

\section{Литература}

1. Алешин К.Н., Максимов С. В. Добровольное сообщение о заключении картеля: назревшие реформы // Российское конкурентное право и экономика. 2018. № 4. С. 24-33.

2. Кулик Я.В. Программа освобождения от ответственности за заключение ограничивающих конкуренцию соглашений // Российское конкурентное право и экономика. 2015. № 3 (16). С. 18-21.

3. Павлов Н. С., Шаститко А. Е. Программа ослабления наказания за участие в картеле // Российское конкурентное право и экономика. 2015. № 1 (14). С. $20-32$.

4. Кодекс Российской Федерации об административных правонарушениях от 30.12.2001 № 195-Ф3 (ред. от 11.10.2018) // СЗ РФ. 07.01.2002. № 1 (ч. 1). Ст. 1.

5. Решение ФАС России о рассмотрении жалобы на постановление по делу об административном правонарушении № 4-14.32-91/00-22-18.

6. Постановление 19 арбитражного апелляционного суда от 28.01.2019 по делу № A08-9287/2016. URL: http://kad.arbitr.ru (Дата обращения: 20.02.2019).

7. Постановление ФАС России от 17.04.2017 по делу № 4-19.5-11/00-08-17.

8. Постановление ФАС Волго-Вятского округа от 12.03.2010 по делу № А29-1325/2009 [Электронный ресурc]. URL: http://kad.arbitr.ru (Дата обращения: 20.02.2019).

9. Решение ФАС России от 14.03.2017 по делу № 1-11-59/00-22-16 в отношении 000 «Эппл Рус» https://br.fas.gov.ru

10. «Обзор законодательства и судебной практики Верховного Суда Российской Федерации за третий квартал 2010 года» (утв. Постановлением Президиума Верховного Суда РФ от 08.12.2010) http://www.consultant.ru (Дата обращения: 20.02.2019).

11. Федеральный закон от 26.07.2006 № 135-Ф3 «О защите конкуренции» // СЗ РФ, 31.07.2006. №31 (ч. 1). Ст. 3434

12. Кодекс Российской Федерации об административных правонарушениях от 30.12.2001 № 195-Ф3 (ред. от 11.10.2018) (с изм. и доп., вступ. в силу с 29.10.2018) // СЗ РФ. 07.01.2002. № 1 (ч. 1). Ст. 1.

13. Определение КС РФ от 05.11.2003 №349-0/2003. URL: http://www.ksrf.ru/ru/Decision/Pages/default. aspx. (Дата обращения: 20.02.2019).

14. Постановление Пленума ВС РФ от 24.03.2005 № 5 «О некоторых вопросах, возникающих у судов при применении Кодекса Российской Федерации об административных правонарушениях». Бюллетень Верховного Суда РФ, № 6, 2005.

15. Постановление КС РФ от 17.01.2013 № 1-П. URL: http://www.ksrf.ru/ru/Decision/Pages/default.aspx (Дата обращения: 20.02.2019). 
Основания смягчения и освобождения от ответственности за нарушение...

16. Постановление КС РФ 25.02.2014 № 4-П. URL: http://www.ksrf.ru/ru/Decision/Pages/default.aspx (Дата обращения: 20.02.2019).

17. Федеральный закон от 31.12.2014 №515-Ф3 «0 внесении изменений в ст. 4.1 Кодекса Российской Федерации об административных правонарушениях». СЗ РФ, 05.01.2015, № 1 (ч. І). Ст. 68.

18. Постановление Пятого арбитражного апелляционного суда от 07.03.2017 № 05АП-230/2017 по делу № A51-17096/2016. URL: http://kad.arbitr.ru (Дата обращения: 20.02.2019).

19. Определение Верховного Суда РФ от 04.07.2018 № 310-АД18-8272. URL: http://kad.arbitr.ru (Дата обращения: 20.02.2019).

20. Постановление Арбитражного суда Поволжского округа от 21.07.2016 № Ф06-10542/2016 по делу № A12-59525/2015. URL: http://kad.arbitr.ru (Дата обращения: 20.02.2019).

21. Постановление Арбитражного суда Северо-Кавказского округа от 17.02.2017 № Ф08-510/2017 по делу № A20-3765/2015. URL: http://kad.arbitr.ru (Дата обращения: 20.02.2019).

22. Постановление Пленума ВС РФ от 24.03.2005 № 5 «О некоторых вопросах, возникающих у судов при применении Кодекса Российской Федерации об административных правонарушениях». Бюллетень Верховного Суда РФ, № 6, 2005.

23. Постановление Пленума ВС РФ от 02.06.2004 № 10 «0 некоторых вопросах, возникших в судебной практике при рассмотрении дел об административных правонарушениях». Вестник ВАС Р. № 8. 2004.

24. Постановление КС РФ 17.01.2013 № 1-П. URL: http:// www.ksrf.ru/ru/Decision/Pages/default.aspx (Дата обращения: 20.02.2019).

25. Постановление ФАС России от 12.10.2017 по делу № АК451-17.

26. Федеральный закон «О контрактной системе в сфере закупок товаров, работ, услуг для обеспечения государственных и муниципальных нужд» от 05.04.2013 № 44-Ф3 (ред. от 27.12.2018). С3 РФ. 08.04.2013. № 14. ст. 1652.

27. Постановление ФАС России от 12.10.2017 по делу № AK448-17.

28. ФАС России. Методические рекомендации по применению статьи 2.9 КоАП РФ (в части прекращения дел об административных правонарушениях, связанных с нарушением антимонопольного законодательства, по малозначительности). URL: http://www.consultant. ru (Дата обращения: 20.02.2019).

29. Постановление Пленума ВАС РФ от 30.06.2008 № 30 «О некоторых вопросах, возникающих в связи с применением арбитражными судами антимонопольного законодательства» (ред. от 14.10.2010). Вестник ВАС РФ. № 8. Август. 2008.

30. Решение Краснодарского УФАС России от 25.07.2018 по делу № 25/2018.

31. Постановление Девятого арбитражного апелляционного суда от 17.08.2012 № 09АП-15752/2012-АК по делу № a40-62153/2011. URL: http://kad.arbitr.ru (Дата обращения: 20.02.2019).

32. Проект Федерального закона «О внесении изменений в Федеральный закон «О защите конкуренции» ID проекта 02/04/10-17/00074495. URL: https://base. garant.ru/56734825

\section{Сведения об авторах}

Акимова Ирина Владимировна: доцент базовой кафедры «Федеральная антимонопольная служба» Финансового университета при Правительстве РФ, руководитель антимонопольной практики Адвокатского бюро BGP Litigation, адвокат

Контактная информация:

Адрес: 123317, г. Москва, Пресненская набережная, д. 6, стр. 2, ДЦ «Империя»

Тел.: +7 (910) 416-79-94

E-mail: irina.akimova@bgplaw.com

Вовкивская Лариса Валерьевна: старший преподаватель базовой кафедры «Федеральная антимонопольная служба» Финансового университета при Правительстве РФ, заместитель начальника Правового управления ФАС России

\section{Контактная информация:}

Адрес: 125993, г. Москва, ул. Садовая Кудринская, д. 11

Тел.: +7 (917) 581-85-75

E-mail: vovkivskay@fas.gov.ru 